con la connaissance rationnelle. ¡Pero esto es la locura!, exclamarán algunos espíritus timoratos. Pero, ¿qué importaría que lo fuera, siendo hermosa? Lo importante es esto último. La emoción estética, como toda emoción, no es un acto del razonamiento. ¿Por qué querer, entonces, que la poesía sea comprensible - si nunca lo ha sido-, exigiendo esta cualidad como elemento indispensable para sentir su belleza? ¿A qué se debe la emoción estética que despierta en los hombres-aun en los más incultos-la Gioconda de Leonardo? ¿Es un producto de la razón, de la comprensión? No, puesto que jamás se había pensado en ella y en ella no hay nada que sea necesario comprender. Si se exigiera de un hombre que explicara los motivos que han influído en su emoción, no sabría qué decir. Una esteta tal vez lo díría. Pero eso no tiene importancia; lo que quiero hacer notar es que no fué necesaria la explicación para sentir la emoción. Lo mismo sucede en poesía, en toda la poesía, la de ayer y la de hoy. Aquel a quien no le gusta o no la siente, no intente comprenderla; perderá su tiempo. Y aquel que gustándola intente también comprenderla, creyendo así llegar a gustarla más, perderá, además del tiempo, la sensación de belleza que le había dado. Así está planteada la cuestión. «La explicación del teorema de Pitágoras - me dice un amigo-produjo en mí una especie de deslumbramiento. " Lo creo. La razón tiene también sus goces, pero no olvidemos dar a la geometría lo que es de la geometría y a la poesía lo que es de la poesía.-M A N U L R J A s.

\title{
SOBRE LAS REVOLUGIONES DE ARGENTINA, PERÚ Y BOLIVIA
}

\section{Tres movimientos distintos y una sola crisis económica verdadera.}

鳟 $\mathrm{S}$ ingenuo suponer que las caídas de Siles, Leguía e Irigoyen se han producido por razones de contagio, como una propagación de grippe. Ha habido, entre ellas, influencia indirecta: inquietud pública, popularización de los actos de fuerza, crisis del respeto a la autoridad. Pero estos factores sólo pueden ser secundarios en. un movimiento, y así lo prueba su limitada eficacia, detenida en las fronteras de otros regímenes personalistas. Además, si fueran reacciones exclusi- 
vamente contra las tiranías, no se explicaría la caída de Irigoyen, quien, aunque empírico, monomaníaco y absorbente, estaba penetrado de un profundo concepto popular y argentinista. Tampoco obedecen a abstractos principios democráticos, pues aunque las juntas se anuncian transitorias, lo cierto es que han cristalizado en sistemas enérgicos y omnímodos. Finalmente, Perú soportaba su gobierno desde hace once años, Bolivia desde hace cinco y Argentina desde hace dos. ¿Por qué se han producido los pronunciamientos simultáneamente?

Si analizamos las alternativas económicas de estos países veremos que los tres movimientos, aunque distintos e independientes, obedecen a una sola crisis verdadera. Como no somos teólogos católicos, procuremos llegar a las entrañas de este aserto, distanciándolo así de su paralelo trinitario. Repasemos, someramente, las condiciones de la infraestructura economica para observar, después, su paralelo en la superestructura política.

Una de las contradicciones del sistema capitalista, la más trágica sin duda, es la que afecta a la industria, condenada a poder producir mucho más de lo que consume el mercado. La perfección técnica, acrecentada a diario, agiganta este distanciamiento. Según estadísticas últimas, puede calcularse que la industria del mundo trabaja a un $55 \%$ de su capacidad real. Pues bien, aunque el estadio monopolista, es decir, imperialista, del capitalismo, ha permitido un control creciente sobre la producción, ésta aún no puede salir de su condición anárquica. Después de la guerra, deseosa de recuperar el terreno perdido, la industria forzó sus rendimientos, multiplicando sus productos. Pero los mercados no bastaban para digerir tanta producción. Asia, Africa, América, España, etc., condenados a ser mercados de consumo, no resolvían el conflicto. La superproducción fué cada vez mayor. Este exceso, al par que la desmesurada especulación bolsística de los valores industriales, determinaron el colosal crack que afectó la economía norteamericana en 1929. Las anteriores catástrofes financieras se caracterizaron por ser de tipo bancario. En cambio, esta ultima afectó, muy específicamente, a las grandes manufacturas. Una de las consecuencias inmediatas y lógicas de tal crisis fué la disminución de la producción industrial, no sólo porque se preveía una contracción en el mercado universal de consumos, sino porque había de darse salida a la enorme superproducción acumulada. Al disminuirse la producción industrial, por rechazo o efecto natural e imprescindible, disminuyo el consumo de las materias primas. 


\section{Nuestro papel colonial en la economía del mundo}

Nada prueba mejor el ilusionismo de nuestra actual independencia, fundamentada en símbolos externos, pero no en la posesión efectiva de todos los factores que integran la Nación: tierra, economía, etc., que el efecto que esa disminución en el consumo de materias primas produjo en casi todos nuestros países.

Apenas dejaron de comprarse éstas, disminuyb el valor y la cantidad de productos exportados en América. Como quien golpea la primera bocha de una larga fila, esta medida golpe6, sucesivamente, todos los planos de las deformadas economías latinoamericanas. Disminuy6 el trabajo agrario, el de los ferrocarriles y puertos, provocando desocupación y el consiguiente malestar social. La clase dominante, al ver disminuídas sus ganancias, redujo sus actividades comerciales, descendiendo las construcciones, las compras, los gastos, etc. Se operó, pues, una contracción en el intercambio de actividades útiles. Los créditos aumentaron en volumen, subiendo, también, la tasa respectiva. Una alarma general preparó el terreno, para una crisis mayor. Disminuídas las entradas del Estado, por el descenso del producto de los impuestos a las exportaciones y de los otros impuestos, los Gobiernos se vieron en la necesidad de recurrir a empréstitos cuando podían utilizar el crédito, - de introducir economías heroicas cuando no disponían de él.

En síntesis: un año después del crack bursátil en Nueva York la mayor parte de nuestros Estados, que apoyan sus pies en la explotación de los dos o tres "productos nacionales»: (estaño en Bolivia, cobre y algodón en Perú y granos en Argentina) se sentían hundir, arrastrados por la caída de sus respectivos "productos nacionales".

Veamos esto más de cerca. Bolivia, según su presupuesto fiscal, percibe la tercera parte de sus rentas de la explotación del estaño. A principios de 1930 la producción de estaño comienza a decrecer. Paulatinamente se observan los efectos de este descenso en la economía boliviana. Disminución de trabajo en la zona minera y desocupación; mayor explotación en los trabajadores (empleados y obreros), que continuaban en servicio: contracción de las actividades comerciales y, principalmente, disminución de los ingresos del Estado. La impericia del gobierno y su dependencia de las grandes empresas imperialistas, de las cuales era instrumento, le impedían aumentar las entradas mediante imposiciones directas 
al capital. Su papel colonialista se precisó en el terreno político. Acudio entonces a aumentar los impuestos indirectos, que encarecen la vida y gravitan sobre el pueblo, y a disminuir los sueldos y salarios. Consiguientemente amplió su régimen de fuerza, para contener las iras populares. La situación se hizo incómoda porque la caldera trabajó a toda presión. Los círculos áulicos advirtieron que el dinero no corría abundantemente y abandonaron a Siles. Quedó un círculo pequeño, debilitado, medroso. Estalló el movimiento de Villazón y el gobierno bambolebse, herido gravemente. Hinojosa no fué secundado por quienes se comprometieron a ello, pero el movimiento se puso en marcha. Los conservadores opuestos a Siles se acoplaron hábilmente a la lucha y resultaron sus usufructuadores. Ya volveremos, desde un punto de vista general, sobre esta característica. Veamos, ahora, el caso del Perú.

Leguía, vendiendo las riquezas nacionales, contratando empréstitos onerosos, fuera de la capacidad real del país, disfrut6 durante once años de colosales sumas de dinero. Ellas le permitieron recompensar generosamente a su corte palaciega y rodearse de toda clase de medidas de fuerza. La abundancia de dinero era su mejor capa protectora, su coraza.

Numerosas obras públicas garantizaban trabajo, coimas, ganancias. Pero ese desatentado régimen de despilfarro del "hábil economista", tan parecido al de un novel heredero que venda o empeñe todo lo que heredó, tenía un término forzoso. Entregado al imperialismo cuanto bien público había en Perú, concedidos todos los monopolios posibles, prestada una suma fabulosa de dinero, llegó el momento de pagar. El empréstito exigía el impuesto. Pero Leguía, como Siles, no podía gravar las utilidades del imperialismo, ni las del capital bancario. Eran su producto, su expresión. Gravó, entonces, la vida común: impuestos a los fósforos, nafta, monopolio de carne, etc. La caldera empezó a tomar presión. El cinematográfico "progreso" llegaba al último acto, y entonces hubo desocupación profesional, de empleados y de obreros. Los banqueros negaron nuevos empréstitos. El heredero no tenía nada que vender. Se aprovecharon de él, entonces, obligándolo a pactos internacionales que favorecían, en primer término, conveniencias norteamericanas. A Leguía sólo le quedaron la fuerza, el terror, el dispendio. Pero en esa época la crisis mundial comenzó a sacudir al Perú. Disminuyó la exportación de cobre, de azúcar, de algodón. La clase aristocrática, vinculada a las dos últimas, acrecento su hostilidad al gobernante que no sabía defenderla frente a las tarifas de EE. UU. El 
volumen comercial se contrajo. Hubo desocupación y miseria. S6́lo el petróleo, en manos de la Standard Oil, continuaba y continúa rindiendo grandes utilidades. Pero el petróleo no tiene un gravamen importante en el Perú. En 1928, apenas dej6 6 millones de soles. Leguía lo respeto, como buen agente del imperialismo. La crisis no ofrecía salidas. Los áulicos se retiraron a resguardar las fortunas mal habidas. La caldera tomó toda su presión. Al primer estallido revolucionario, Leguía, el hombre de «carácter», el tirano de hierro, se vino abajo como un muñeco de vidrio. La crisis económica lo había minado, corroído. Ya no era sino la cáscara, la apariencia.

Argentina es un país eminentemente agropecuario. Su actividad económica, pues, está vinculada a su comercio de exportación, El $60 \%$ de éste lo constituyen los granos, especialmente el trigo, maíz y lino. Las tarifas arancelarias yanquis, la crisis mundial, la superproducción, minaron rápidamente la producción granera. En menos de un año, el comercio de exportación déscendió en un $30 \%$ de su valor y en un $35 \%$ de su volumen. El camino de prosperidad por donde Argentina marchaba un tanto ufana of recí, así, un brusco precipicio.

Inmediatamente se advirtieron los mismos efectos que hemos señalados en los casos anteriores. Irigoyen tuvo que contratar un empréstito de 50 millones de dólares para atender a la disminución de los ingresos del Estado. Pero la crisis, lejos de disminuir, aumentó. La cląse terrateniente, conservadora y jerárquica, arrecíb su oposición al régimen urbano y populista que no sabía auxiliarla en ese trance. Tal fué el significado profundo de la silbatina al Ministro de Agricultura en la Sociedad Rural, sede de aquella. Entre tanto, el Gobierno permaneció sumido en sus cavilaciones electorales. El país marchaba a un caos, contraído su volumen económico. El Estado, lejos de conjurar el problema científicamente, echó manos de las reservas del Banco de la Nación, provocando pánico. La oposición multiplicó su esfuerzo. Irigoyen creyó que bastaría su nacionalismo para defenderse. Sabía que su legislación petrolera y sus disposiciones sobre precio único a la nafta producen ingentes pérdidas al imperialismo petrolero norteamericano que, sólo por el último concepto, deja de ganar 25 millones de pesos al año, jes decir, dos por mes! Irigoyen creyó que el pueblo, vaga entelequia que presidió todos sus sueños idealistas, habría de protegerlo conociendo este argentinismo efectivo. Pero el pueblo estaba dominado por otros factores. Irigoyen no adoptó medidas de fuerza, en tanto que sus enemigos, la Standard incluso, disparaban contra él desde todos los 
ángulos. Revocó las brdenes de prisión, mantuvo las libertades de prensa y de reunión. Cuando quiso reaccionar, era tarde. La revolución estaba encima, e Irigoyen fué barrido del gobierno con el viento del primer sable militar.

El análisis, aunque somero, de los casos Bolivia, Perú y Argentina, nos hace ver, pues, cómo la crisis económica mundial derribó a tres gobiernos de países cuya economía aún es dependiente y colonial.

\section{La solución conservadora y la solución socialista}

A proposito de la revolución boliviana, of recimos volver sobre los usufructuarios de la revolución. En efecto, conviene hacerlo porque nada demuestra mejor el carácter económico de estos cambios políticos que el hecho de haber sido realizados, o aprovechados, por los intereses de los grandes terratenientes respectivos.

En Bolivia, donde la crisis pudo derivarse en un movimiento social como quería Hinojosa, la revolución ha cristalizado en una trinidad presidencial que no permite errar, en un triángulo típicamente conservador, feudal y dictatorialista. Dos de los vencedores, expresidentes del país, fueron, en sus respectivos gobiernos, despóticos y abusivos. El tercero sólo será un instrumento. Históricamente, frente a la crisis boliviana, la clase terrateniente y minera ha reemplazado el régimen híbrido de Hernando Siles. El imperialismo yanqui es respetado en cuanto a empréstitos, concesiones, propiedades petroleras, etc. La clase terrateniente se satisface con apoderarse del Gobierno para favorecer su situación.

Igual cosa amenaza ocurrir en Perú. Los señores terratenientes del civilismo asoman sus cabezas detrás de la Junta Militar y ya descuentan ser los próximos gobernantes constitucionales del país. El algodón y el azúcar se aseguran, así, la protección oficial, o mejor dicho, gobernarán al Perú, de no oponérseles una resistencia enérgica. Cauta y habilidosamente se han colocado junto al gobierno militar, disfrazados de salvadores de la patria, pero en realidad para salvarse a ellos mismos. El imperialismo por otra parte, con la revolución peruana ve cerrarse, provisionalmente, las puertas de futuras franquicias. Pero, como hasta ahora ha sido respetado en sus intereses vitales: petróleo, cobre, oro y plata, empréstitos, etc., no se muestra perjudicado ni intranquilo.

Fuera de los partidos actuantes, la Junta argentina representa, sin embargo, el clásico criterio conservador. Todos sus 
hombres pertenecen a la aristocracia, vinculada estrechamente a los terratenientes. Fl maíz, el trigo y el lino se han tomado, así, venganza contra el régimen callejero de Irigoyen y han asegurado la administración del Poder desde un punto de vista favorable a sus intereses. Fl imperialismo petrolero, que cuenta con abogados de gran influencia actual, aspirará, por todos los medios, al cambio de la legislación petrolera que tanto le perjudica.

Resumiendo, dentro de una generalización forzosa, y previendo la consumación de hechos aún no realizados totalmente, puede decirse que la crisis económica provocada en los países productores de materias primas, o sea crisis producida por el imperialismo y por el papel colonial y dependiente de nuestra economía, se ha resuelto en un avance franco y decidido de la clase terrateniente hacia el poder, la cual respetando la invasión imperialista en los otros brdenes, se contenta con salvaguardar enérgicamente sus intereses, sacrificando, en todo caso, a las clases productoras. Tal solución es, evidentemente, una solución conservadora.

Nuestro movimiento aprista tiene una significación radicalmente distinta. Precisamente como hemos venido señalando los peligros del imperialismo, los acontecimientos no nos toman de sorpresa. Frente al avasallador avance del capital imperialista, sostenemos que es necesario condicionar sus entradas, sujetándolo no sólo a la legislación sino también a las conveniencias del país. La única forma efectiva de obtenerlo es ir hacia la progresiva nacionalización de las industrias fundamentales. E1 Estado antimperialista es la única garantía de que el imperialismo no abusará de sus privilegios y potencia. Las clases productoras, empleados y obreros de las industrias, encontrarán en ese Estado el apoyo y el salario que hoy les niega el Estado terrateniente. Las utilidades serán legítimamente repartidas y no serán monopolizadas por los extranjeros y una minoría de lacayos. La tierra también debe ser nacionalizada para redimir a los campesinos de su esclavitud, para renovar los métodos del cultivo mediante sistemas intensivos y científicos. Pero, sobre todo, el Estado antimperialista, síntesis de las fuerzas oprimidas por el imperialismo, procurará el crecimiento armónico del país, sin fundamentar su economía sobre dos o tres pilares inestables y a merced de los vaivenes mundiales, desarrollando las fuerzas efectivas de la nación en un sentido progresista, justiciero y normal. Fntonces habrá efectuado la verdadera independencia economica. Las crisis de los países más adelantados sólo repercutirán indirectamente 
sin causar las catástrofes que ahora contemplamos. Bolivia será boliviana, Perú será peruano, Argentina sera argentina. Esta acción se integrará buscando en los otros planos de la vida humana el esfuerzo concurrente que la convierta en acción integral. Rotos los vínculos con el feudo económico y con el imperialismo avasallante, el Fstado, ya efectivamente libre, podrá afrontar los problemas dependientes, como los derivados de la educación, la salubridad, las relaciones con la Iglesia, la función social del trabajo y la austeridad como norma de una vida mejor.

Esta solución, entonces, dentro de marcos socialistas, es una solución profunda y auténticamente nacionalista. Nuestro nacionalismo verdadero, sin sus viejas raíces sentimentales, es un método del que se ha extirpado toda aquella floración que lo vuelve inútil ciertas veces, o que no es sino el ropaje que disfra$z a$ aviesas intenciones, en otros casos. Nuestro nacionalismo, nacido al calor de la comprensión continental de nuestros problemas, y bajo ideales de fraternidad entre los hombres, repité por eso su viejo lema: "tenemos un solo y grande enemigo;-formemos una sola y grande unión».-M A N U E L A. S E O A N E.

Exclusivo para Atenea en Chile.

\section{CONFESIONES DEL TIEMPO}

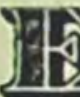
STA dicho que toda la peripecia de nuestra vida consiste en preferir unas cosas y desdeñar otras. Tal es el cauce por donde se va deslizando nuestra íntima personalidad y en el cual ella se busca, se reconoce y se revela a sí misma. Allí, pues, donde se ha posado nuestra preferencia es posible sorprender algo de lo que somos. Porque preferimos unas cosas y no otras, y desdeñamos éstas y no aquéllas debido a que nuestro ser está hecho de una determinada manera. Lo cual es $\tan$ evidente $\mathrm{y}$ puede of recerse con $\tan$ acentuado radicalismo que, por lo general, quedan sus términos reducidos a un percibir ciertas cosas y a un no percibir todas las restantes.

Así es cómo en las lecturas elegidas, lo mismo que en el amor, cada cual, aunque no lo quiera, hace su propia confesión. Quien declara los nombres de sus autores y libros preferidos lo que efectúa en última instancia es esto: proyectar afuera algo de su panorama íntimo, regalar su secreto de tal modo que alguien podría advertir lo que en él es rico y lo que anda menguado. En todos los que leen existe, por lo menos vagamente, la conciencia 